\title{
Flame-Retardant and Smoke Suppression Properties of Nano MgAl-LDH Coating on Bamboo Prepared by an In Situ Reaction
}

\author{
Xiaoling Yao $\mathbb{D}$, ${ }^{1}$ Chungui Du $\mathbb{D},{ }^{1,2}$ Yating Hua, ${ }^{1}$ Jingjing Zhang $\mathbb{D}^{1},{ }^{1}$ Rui Peng $\left(\mathbb{D},{ }^{1}\right.$ \\ Qiuli Huang $\left(\mathbb{1},{ }^{1}\right.$ and Hongzhi Liu ${ }^{1,2}$ \\ ${ }^{1}$ School of Engineering, Zhejiang A\&F University, Hangzhou 311300, China \\ ${ }^{2}$ Zhejiang Provincial Collaborative Innovation Center for Bamboo Resources and High-Efficiency Utilization, \\ Hangzhou 311300, China
}

Correspondence should be addressed to Chungui Du; chunguidu@163.com

Received 24 December 2018; Revised 7 March 2019; Accepted 23 April 2019; Published 22 May 2019

Academic Editor: Bo Tan

Copyright (c) 2019 Xiaoling Yao et al. This is an open access article distributed under the Creative Commons Attribution License, which permits unrestricted use, distribution, and reproduction in any medium, provided the original work is properly cited.

\begin{abstract}
In recent years, bamboo has been widely used for building materials and household goods. However, bamboo is flammable, so a flame-retardant treatment for bamboo is urgently needed. In this work, nano MgAl-layered double hydroxide (MgAl-LDH) coated on bamboo, which was called MgAl-LB, was synthesized by an in situ one-step method. To determine the optimal in situ time, the effects of different reaction times on $\mathrm{LDH}$ growth on the bamboo surface and the flame retardancy of the MgAl-LBs were investigated. The SEM observations show that LDH growth on the surface of bamboo was basically saturated when the in situ reaction time was $24 \mathrm{~h}$. Abrasion experiments show that MgAl-LDH coating has good abrasion resistance. The fire performance of the MgAl-LBs was evaluated by cone calorimeter tests, which indicated that the THR and TSP of the MgAl-LBs were significantly lower than those of untreated bamboo. Taking into account the energy consumption problem, determining the reaction time of $24 \mathrm{~h}$ is the optimal reaction time. Compared with untreated bamboo, the THR and TSP of MgAl-LB prepared at $24 \mathrm{~h}$ decreased by $33.3 \%$ and $88.9 \%$, respectively.
\end{abstract}

\section{Introduction}

In recent years, the demand for wood resources has gradually increased, but natural forestry is protected in China [1]. Therefore, people need an alternative to wood. Bamboo has the characteristics of fast growth, high yield, and good mechanical properties $[2,3]$. Therefore, bamboo can be used instead of wood in some fields. Due to the unique appearance of bamboo, its products are already being used by people as decorative materials in buildings; however, the flammability of bamboo leads to its limited use in indoor environments. Thus, flame-retardant bamboo material is important.

Layered double hydroxides (LDHs), also known as hydrotalcite-like compounds or anionic clay, are mainly composed of positively charged hydroxide layers and negatively charged interlayer anions $[4,5]$. LDHs have chemical composition tunability and interlayer anion exchangeability, which endow them with unique properties and functions.
Therefore, LDHs have a wide range of applications in many fields, such as catalysts [6], adsorbents [7], corrosion protection [8], and flame-retardant materials $[9,10]$. Some studies have shown that LDH can absorb a large amount of heat, dilute the concentration of flammable gas, and absorb harmful acid gases during the decomposition process; therefore, it is an excellent flame retardant [11]. Guo et al. applied MgAl$\mathrm{LDH}$ to wood in a two-step process and found that the total smoke production and maximum smoke production ratio were reduced by $58 \%$ and $41 \%$, respectively, compared to those of samples without MgAl-LDH [12]. Liang et al. introduced $5.0 \mathrm{wt} \% \mathrm{MgAl}-\mathrm{LDH}$ and $5.0 \mathrm{wt} \%$ melamine pyrophosphate to medium density fiberboards and found that the peak heat release rate (PHRR) and mean heat release rate (MHRR) were reduced by $27.9 \%$ and $7.5 \%$, respectively, compared to those of samples with $3.3 \mathrm{wt} \% \mathrm{MgAl}-\mathrm{LDH}$ and $6.7 \mathrm{wt} \%$ melamine pyrophosphate [13]. Wang et al. reported the synthesis of $\mathrm{ZnAl}-\mathrm{LDH}$ coating on the surface of wood to enhance 
the fire resistance of wood [14]. However, as far as we know, no report currently exists on the flame retardancy of bamboo used by MgAl-LDH.

In this study, unlike the abovementioned application of LDHs as a wood fire retardant, MgAl-LDH coated on bamboo (MgAl-LB) was prepared by a one-step method, and the flame-retardant properties of MgAl-LBs prepared under different reaction times were analyzed. In addition, it was found through abrasion experiments that MgAl-LDHs synthesized on the surface of bamboo by this method had good abrasion resistance. The structure and chemical composition of MgAl-LDH on the bamboo surface were analyzed by Xray diffraction, transmission electron microscopy, Fourier transform infrared spectroscopy, and elemental analyses. Scanning electron microscopy was used to observe the morphology and distribution of MgAl-LDH on the surface of bamboo. The combustion decomposition behavior of the MgAl-LB was tested using a combined thermogravimetric and infrared instrument and a cone calorimeter. The abrasion resistance was confirmed by abrasion tests and contact angle measurements.

\section{Materials and Methods}

2.1. Materials. Bamboo strips $\left(100 \times 20 \times 5 \mathrm{~mm}^{3}, L \times T \times R\right)$ were purchased from Zhejiang Yongyu Bamboo Joint-Stock Co. Ltd. Milky white glue was purchased from Shanghai Zhongnan Building Materials Co. Ltd.

Magnesium nitrate hexahydrate $\left[\mathrm{Mg}\left(\mathrm{NO}_{3}\right)_{2} \cdot 6 \mathrm{H}_{2} \mathrm{O}\right.$, analytical grade], aluminum nitrate nonahydrate $\left[\mathrm{Al}\left(\mathrm{NO}_{3}\right)_{3} \cdot 9 \mathrm{H}_{2} \mathrm{O}\right.$, analytical grade], and urea $\left[\left(\mathrm{NH}_{2}\right)_{2} \mathrm{CO}\right.$, analytical grade] were supplied by Sinopharm Chemical Reagent Co. Ltd. (Shanghai, China). Deionized water was used throughout the experiment.

2.2. Fabrication of the MgAl-LBs. First, $750 \mathrm{~mL}$ deionized water was added in the beaker, then $\mathrm{Mg}\left(\mathrm{NO}_{3}\right)_{2} \cdot 6 \mathrm{H}_{2} \mathrm{O}$ and $\mathrm{Al}\left(\mathrm{NO}_{3}\right)_{3} \cdot 9 \mathrm{H} 2 \mathrm{O}$ were added in a molar ratio of $\mathrm{Mg}: \mathrm{Al}=3: 1$, and $\left(\mathrm{NH}_{2}\right)_{2} \mathrm{CO}$ was added in a molar ratio of urea : $\mathrm{NO}_{3}{ }^{-}=3$. The mixture was then stirred to obtain a transparent solution. Six bamboo strips were placed in a $1000 \mathrm{~mL}$ threeneck flask under vacuum for $30 \mathrm{~min}$. Then, the transparent solution was added to the three-neck flask and the bamboo strips were soaked under atmospheric pressure for $1 \mathrm{~h}$. The three-neck flask was transferred to a $100^{\circ} \mathrm{C}$ oil bath and maintained for a specified reaction time $(6 \mathrm{~h}$, $12 \mathrm{~h}, 24 \mathrm{~h}, 36 \mathrm{~h}$, or $48 \mathrm{~h}$ ). When the reaction was over, the stirring was stopped and the temperature was maintained for 10 hours to decompose the remaining urea. Then, the samples were cleaned and rinsed with water. The final samples were freeze-dried in a freeze dryer. The samples are called MgAl-LB-6h, MgAl-LB-12 h, MgAl-LB-24h, MgAl-LB-36 h, and MgAl-LB-48 h.

2.3. Characterization. X-ray diffraction (XRD) was performed using a SHIMADZU XRD-6000 X-ray diffractometer with a $\mathrm{Cu}-\mathrm{K} \alpha$ radiation source (wavelength, $\lambda=0.154 \mathrm{~nm}$ ) at $40 \mathrm{kV}$ and $30 \mathrm{~mA}$ in the range of $5^{\circ}-70^{\circ}$. The composition was determined from the different characteristic

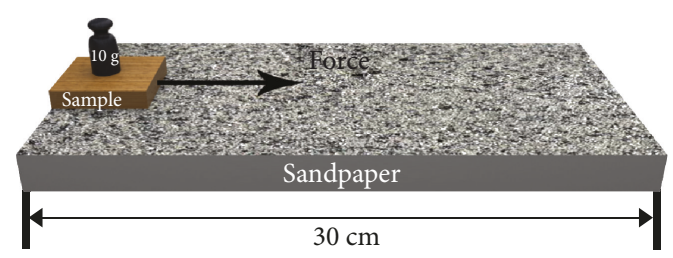

FIgURE 1: Schematic diagram of the abrasion test.

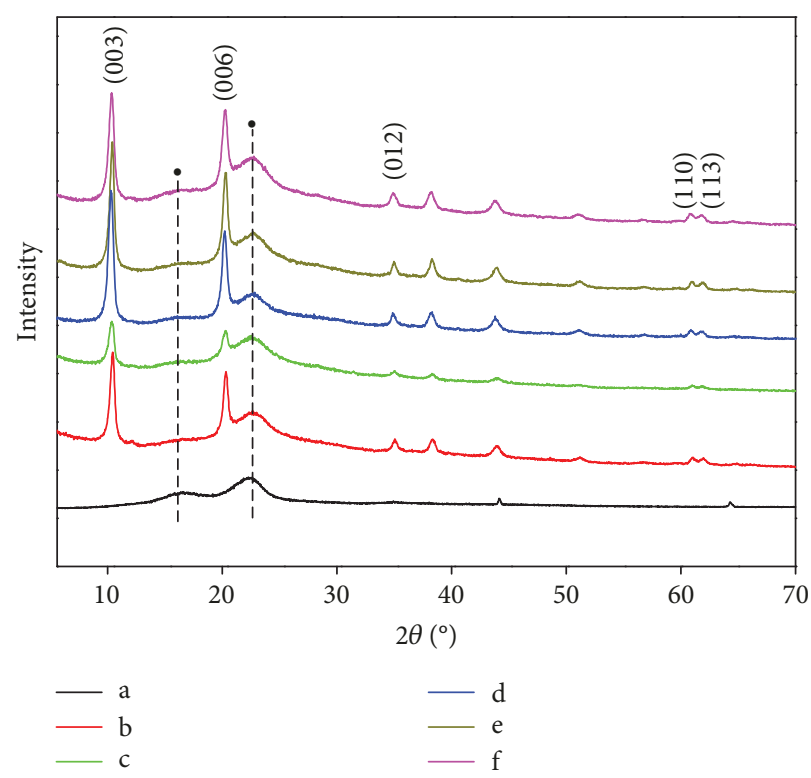

FIgURe 2: The XRD patterns of the untreated bamboo (a), MgAlLB-6h (b), MgAl-LB-12 h (c), MgAl-LB-24h (d), MgAl-LB-36h (e), and MgAl-LB-48 h (f).

peaks, and the $\mathrm{LDH}$ interlayer distance was calculated by the Bragg equation.

Transmission electron microscopy (TEM) images were obtained on a JEM-2010FEF field-emission microscope.

Element analyses of the LBs were carried out using energy dispersive X-ray spectroscopy (EDX) (Genesis 4000, AMETEK, Newark, DE, USA) with an accelerating voltage of $25 \mathrm{kV}$.

The surface and cross-section morphologies of the LBs were imaged with field-emission scanning electron microscopy (FESEM, Hitachi S-4800, Japan).

The combustion tests of the samples were performed by a cone calorimeter test (CCT) (Fire Testing Technology Ltd., East Grinstead, UK) according to ISO 5660-1 procedures (with a stainless-steel grid to prevent samples from bending or extending during combustion). Each specimen (dimensions of $100 \times 100 \times 5 \mathrm{~mm}^{3}$ ) was made up by combining bamboo strips with a small amount of glue, and then, the samples were exposed to an irradiance of $50 \mathrm{~kW} \mathrm{~m}^{-2}$. The test was repeated three times for each sample.

Thermogravimetric (TG) analysis was carried out with a TG 209 analysis system for thermal weight loss analysis in an $\mathrm{N}_{2}$ or air atmosphere at a heating rate of $10^{\circ} \mathrm{C} \cdot \mathrm{min}^{-1}$ from an ambient temperature to $770^{\circ} \mathrm{C}$. 


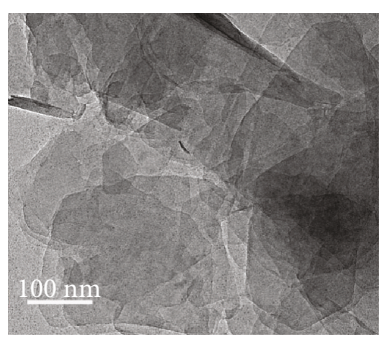

(a)

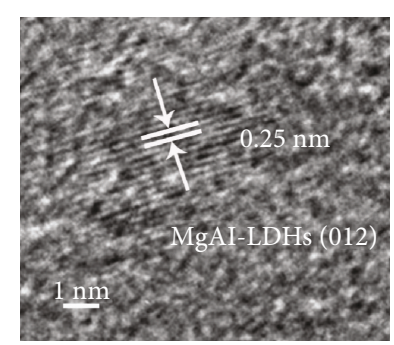

(b)

Figure 3: (a) A typical TEM image of the MgAl-LDH. (b) HRTEM image of the MgAl-LDH.

The abrasion resistance of the MgAl-LDH coating on the bamboo surface was tested by the method in the literature [15]; as shown in Figure 1, MgAl-LB (longitudinal $\times$ tangential $\times$ radial: $10 \times 10 \times 3 \mathrm{~mm}^{3}$ ) was rubbed with a 1500-mesh sandpaper at a pressure of $1000 \mathrm{~Pa}$. The water contact angle of the sample surfaces was measured at every $30 \mathrm{~cm}$ of abrasion length (water contact angle of not less than 5 different positions). The mechanical stability of the MgAl-LDH coating on the surface of the bamboo is judged by the change of the water contact angle.

\section{Results and Discussion}

3.1. Characterization of the MgAl-LBs. Figure 2 shows the XRD curves of MgAl-LBs prepared under different reaction times and untreated bamboo (the powders measured by XRD are scraped off from the surface of the samples with a knife). As can be seen from Figure 2, b-f, the (003), (006), (012), (110), and (113) diffraction peaks of the samples are in agreement with $\mathrm{MgAl}-\mathrm{LDH}$ [16-18] and are ascribable to MgAl-LDH indexed by the JADE 6.0 PDF of No. 890460. In addition, the layer spacing of MgAl-LDH on the surface of MgAl-LBs (6h to $48 \mathrm{~h}$ ) was calculated by the Bragg equation to be $0.89 \mathrm{~nm}, 0.90 \mathrm{~nm}, 0.89 \mathrm{~nm}, 0.90 \mathrm{~nm}$, and $0.90 \mathrm{~nm}$, respectively, which means that the interlayer anions of $\mathrm{MgAl}-\mathrm{LDH}$ on the surface of MgAl-LBs are nitrate ion $\left(\mathrm{NO}_{3}{ }^{-}\right)$[16]. The diffraction peaks at $15.74^{\circ}$ and $22.66^{\circ}$ are ascribable to characteristic diffraction peaks of bamboo (Figure 2, a). Structural information about the MgAl-LDH on the MgAl-LB surface was further obtained by TEM, and the typical TEM image shows that the MgAl-LDHs are present as ultrathin nanosheets (Figure 3(a)). The HRTEM image shows that the interplanar spacing is $0.25 \mathrm{~nm}$ (Figure 3(b)), which corresponds to the (012) plane spacing shown in the XRD pattern.

The elemental composition of MgAl-LBs prepared at different reaction times is shown in Figures 4(a)-4(f). In addition to the $\mathrm{C}$ and $\mathrm{O}$ possessed by the bamboo, $\mathrm{Mg}$, $\mathrm{Al}$, and $\mathrm{N}$ were clearly detected in these samples. It was further confirmed that MgAl-LDH was formed on the surface of bamboo.

3.2. Observed Morphology and Growth Mechanism Analysis of the LDH Coating. Snapshot photographs and SEM images of untreated bamboo and the MgAl-LBs are shown in
Figure 5. The synthesis method and snapshot photographs of untreated bamboo and the MgAl-LB are shown in Figure 5(a). The snapshot clearly shows that the color of the bamboo in the MgAl-LB is significantly more yellow than the untreated bamboo. The reason for the color difference is mainly that the bamboo was at a temperature of $100^{\circ} \mathrm{C}$ for a long time, and the lignin in the bamboo became discolored. In addition, the surface of the MgAl-LB had a white film. It was found by SEM that the surface microscopic morphology of MgAl-LBs has ab-oriented hexagonal platelets compared with untreated bamboo (Figures 5(b)-5(g)), which is similar to the structural appearance reported by other researchers $[12,14,19,20]$. In addition, it was found that the MgAl-LDHs on the surface of MgAl-LBs gradually became denser and denser as the reaction time prolonged (Figures 5(c)-5(g)).

This study also proposed a corresponding mechanism for the formation and growth of LDHs on the surface of bamboo. First, $\mathrm{Mg}^{2+}$ and $\mathrm{Al}^{3+}$ are transported to the surface of bamboo in solution and then adsorbed on the surface of bamboo due to the large quantities of hydroxyl groups on bamboo, as illustrated by steps (I)-(II) in Figure 5(h). In addition, at $100^{\circ} \mathrm{C}$, the urea is slowly hydrolyzed to form $\mathrm{NH}_{3}$, which forms $\mathrm{NH}_{4}(\mathrm{OH})$ in the aqueous solution to provide a suitable $\mathrm{pH}$ for the growth of the MgAl-LDH crystallites. When the local concentration of enriched $\mathrm{Al}^{3+}$ and $\mathrm{Mg}^{2+}$ reaches supersaturation conditions, the nitrate ions embedded in the intermediate layer balance the charge in the solidliquid phase, and then, MgAl-LDHs nucleate at the phase boundary. Finally, an ab-oriented MgAl-LDH film forms on the surface of bamboo [21], as illustrated by steps (III)-(IV) in Figure 5(h).

When the reaction time was $6 \mathrm{~h}$ and $12 \mathrm{~h}$, the MgAl-LDH platelets were partially disordered and perpendicular to the bamboo surface, and some areas of the bamboo surface were not covered by MgAl-LDHs (Figures 5(c) and 5(d)). As the reaction time increased to $24 \mathrm{~h}, 36 \mathrm{~h}$, and $48 \mathrm{~h}$, because of spatial competition, a dense ab-oriented MgAl-LDH membrane formed (Figures $5(\mathrm{e})-5(\mathrm{~g})$ ). Therefore, it can be concluded that as the reaction time is prolonged, a uniform and dense $\mathrm{MgAl}-\mathrm{LDH}$ film is gradually formed. In addition, Figures $5(\mathrm{~b})-5(\mathrm{~g})$ show that the morphology of the MgAl$\mathrm{LDH}$ nanostructures in the dense film on the bamboo surface remains relatively stable for longer reaction times. The results show that a low-energy, dense MgAl-LDH film can be prepared with a reaction time of $24 \mathrm{~h}$. 


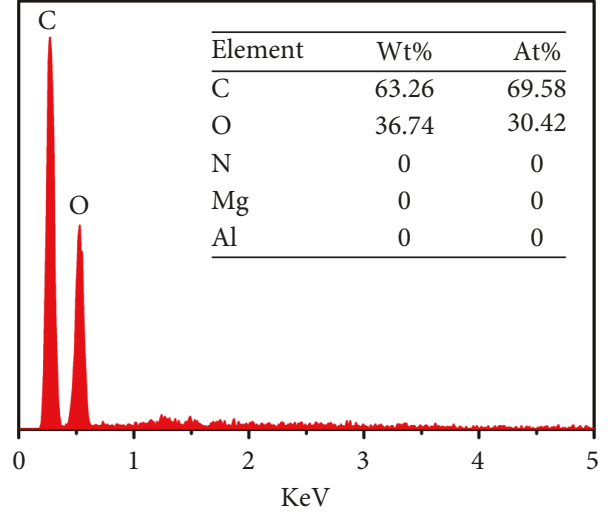

(a)

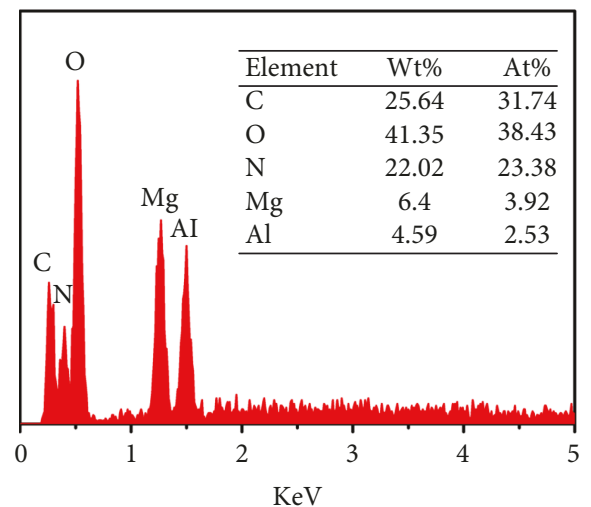

(c)

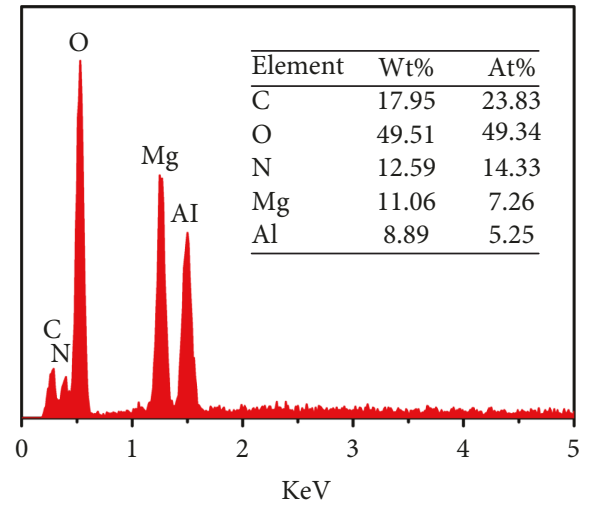

(e)

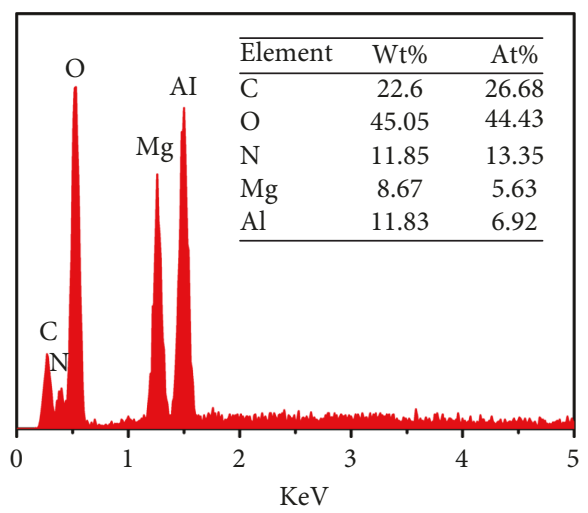

(b)

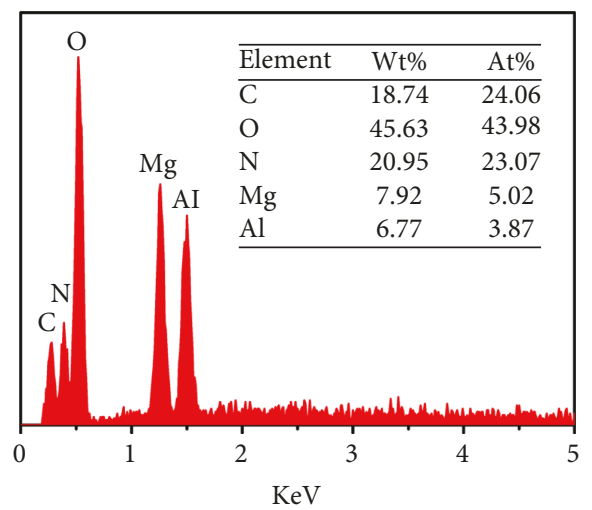

(d)

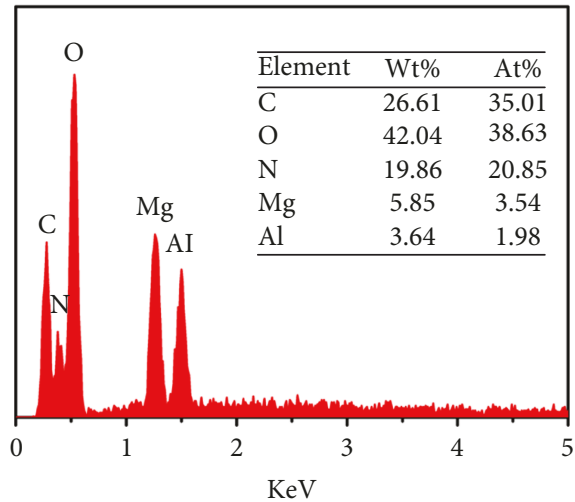

(f)

Figure 4: EDX patterns of untreated bamboo (a), MgAl-LB-6h (b), MgAl-LB-12 h (c), MgAl-LB-24h (d), MgAl-LB-36h (e), and MgAlLB-48 h (f).

3.3. Flame-Retardant Properties. Cone calorimetry was used to obtain combustion information. This technique investigates how materials burn when exposed to the typical heat flux of a fire [22-24]. In this test, the samples were heated in a cone calorimeter, and data were recorded. The heat release rate (HRR), total heat release (THR), smoke production ratio (SPR), total smoke production (TSP), maximum average rate of heat emission (ARHE), and specific extinction area (SEA) plots are shown in Figure 6 , and the parameters evaluated by the CCTs are given in Table 1.
As shown in Table 1, untreated bamboo was ignited after 31 seconds (TTI) with vigorous burning. The TTI of MgAlLBs ( $6 \mathrm{~h}$ to $48 \mathrm{~h}$ ) was delayed by $12.9 \%, 29.0 \%, 35.5 \%$, $45.1 \%$, and $38.7 \%$ compared with untreated bamboo, respectively. This delay could provide valuable time to evaluable time to evacuate a site or extinguish a fire in the event of a fire. As shown in Figure 6(a) and Table 1, the HRR peak value of the MgAl-LBs were smaller than those of untreated bamboo $\left(502.4 \mathrm{KW} / \mathrm{m}^{2}\right)$. As the reaction time prolonged $(6 \mathrm{~h}$ to $48 \mathrm{~h}$ ), the peak HRR decreased from 367.0 to $245.2 \mathrm{KW} / \mathrm{m}^{2}$. The peak value decreased by $26.9 .0 \%, 36.3 \%, 42.9 \%, 46.1 \%$, 


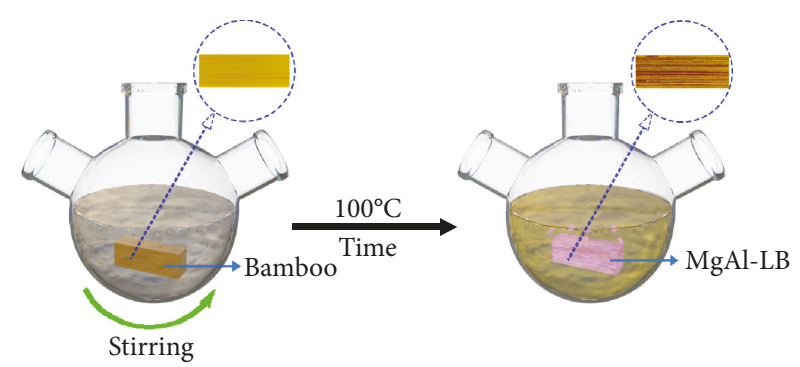

(a)

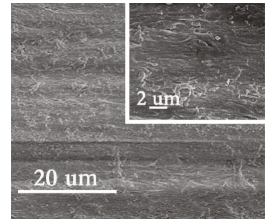

(b)

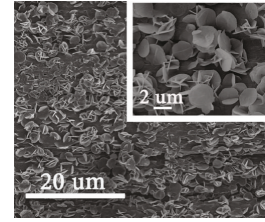

(d)

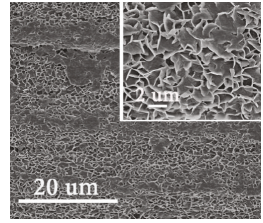

(f)

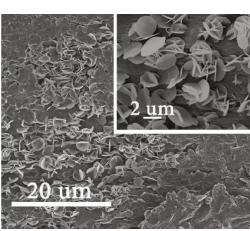

(c)

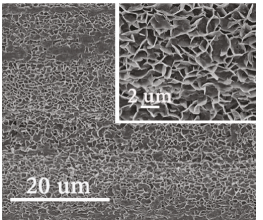

(e)

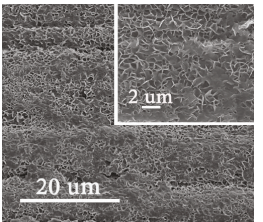

(g)

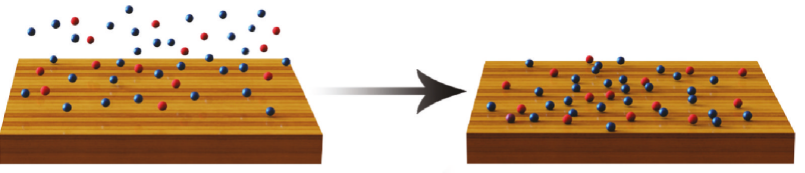

(i)

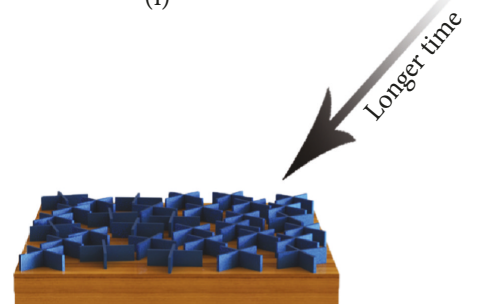

(iv) (ii)

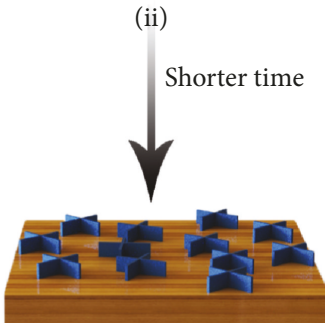

(iii)

- $\mathrm{Mg}^{2+}$

- $\mathrm{AI}^{3+}$

MgAl-LDHs

(h)

Figure 5: (a) Synthetic scheme for the MgAl-LB and snapshot photographs of untreated bamboo and MgAl-LB. SEM images of (b) untreated bamboo, (c) MgAl-LB-6 h, (d) MgAl-LB-12 h, (e) MgAl-LB-24h, (f) MgAl-LB-36 h, and (g) MgAl-LB-48 h. (h) Schematic diagram of LDH film formation.

and $51.2 \%$ compared to that of untreated bamboo for the different reaction times. The THR value of untreated bamboo was $38.6 \mathrm{MJ} / \mathrm{m}^{2}$, and the THR values of the MgAl-LBs ( $6 \mathrm{~h}$ to $48 \mathrm{~h}$ ) decreased by $23.1 \%, 30.0 \%, 33.3 \%, 33.6 \%$, and
$31.3 \%$, respectively, compared with untreated bamboo (Figure 6(b) and Table 1).

The smoke generated by fire is toxic and opaque and seriously endangers personnel safety [25]; therefore, it is 


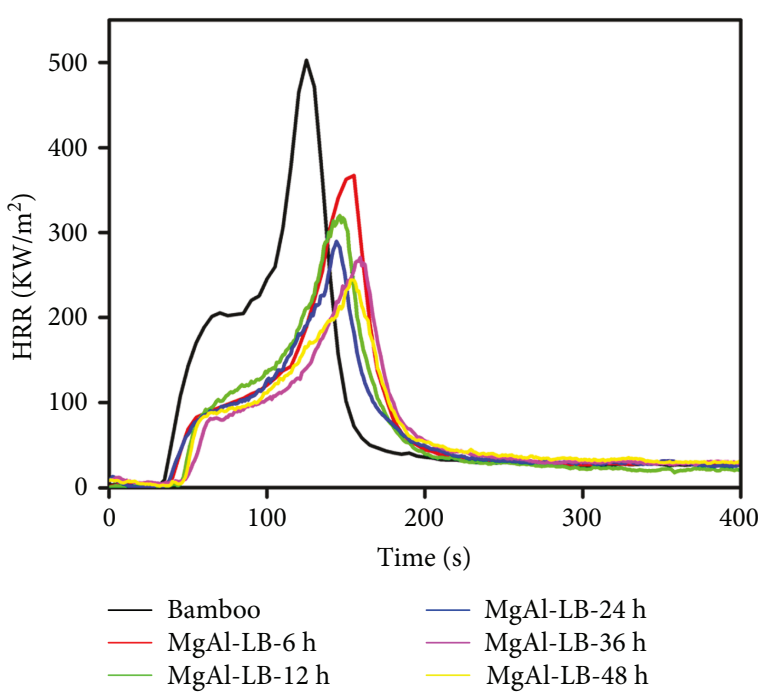

(a)
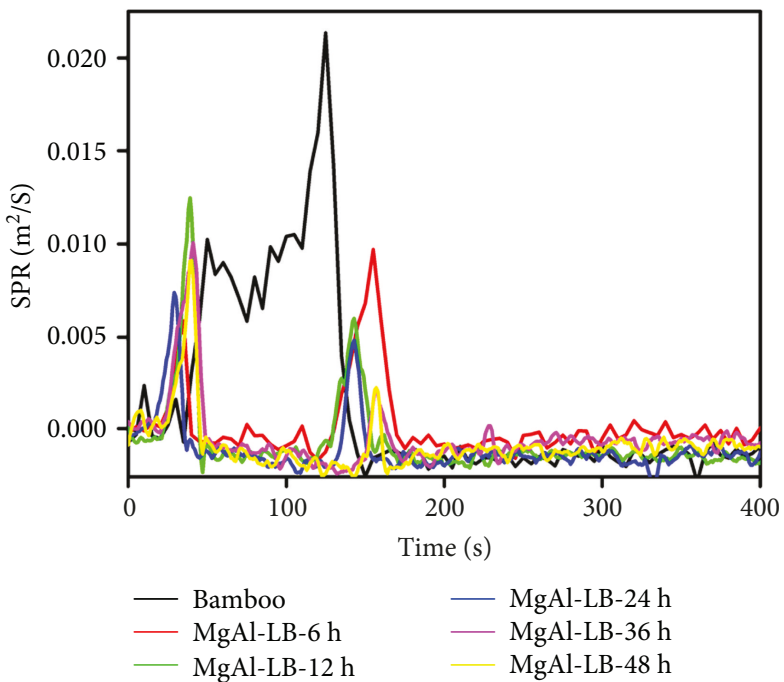

(c)

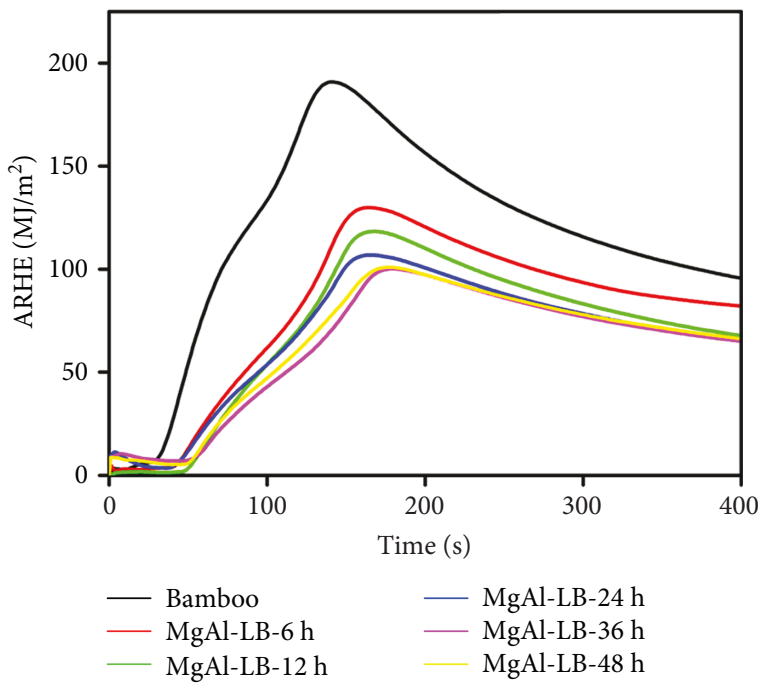

(e)

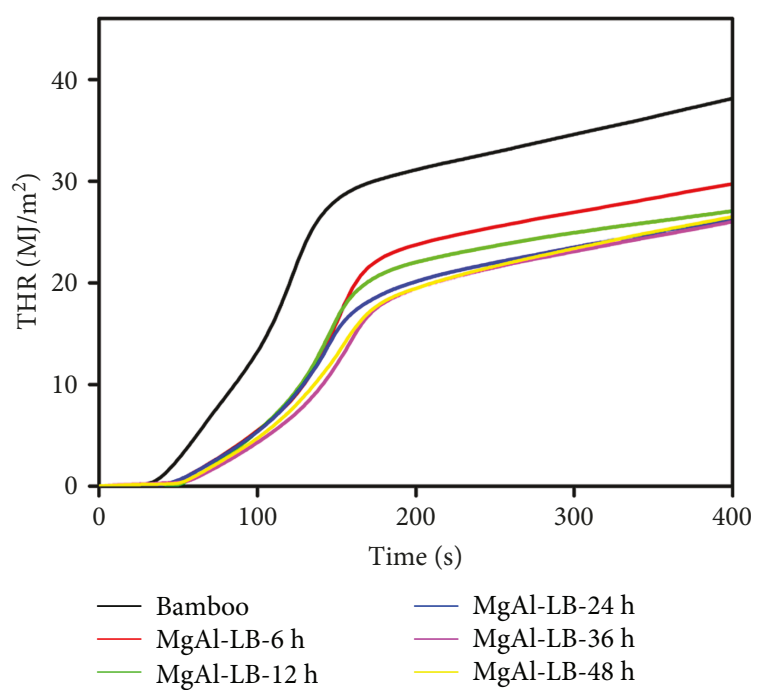

(b)
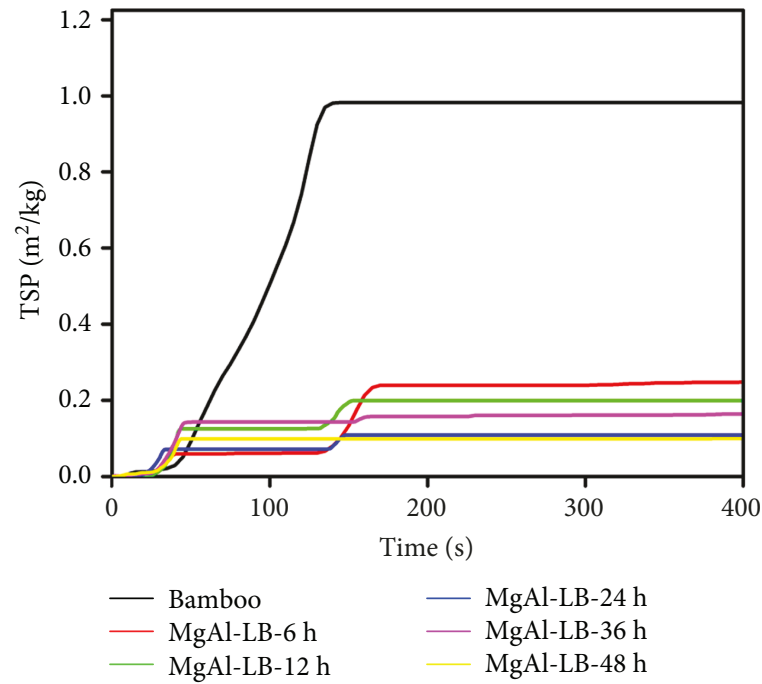

(d)

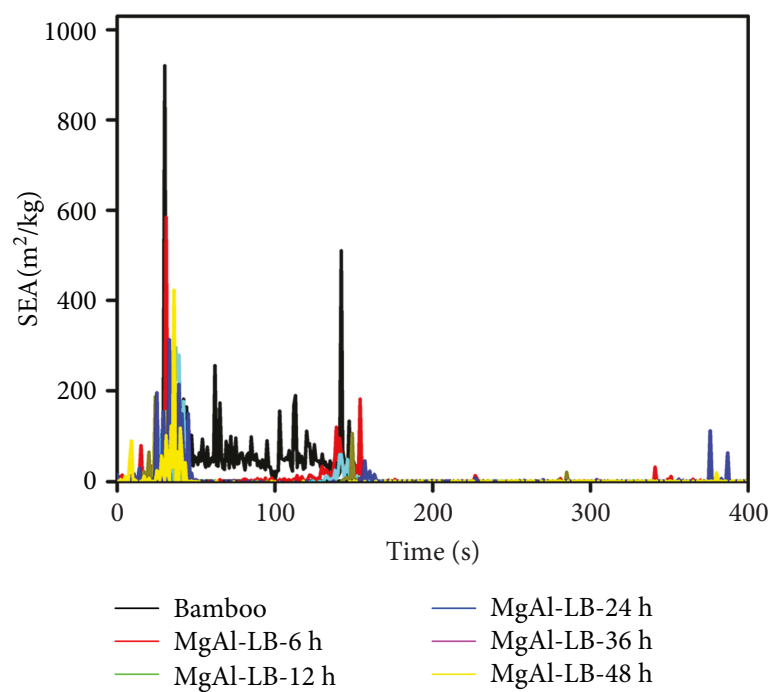

(f)

FIGURE 6: Cone combustion tests of bamboo and MgAl-LBs prepared with different reaction times: (a) heat release rate, (b) total heat release, (c) smoke production ratio, (d) total smoke production, (e) maximum average rate of heat emission, and (f) specific extinction area. 
TABLE 1: Values of the parameters from the CCTs: time to ignition (TTI), peak of HRR (pkHRR), THR, SPR, TSP, MARHE, and residue values (Wres).

\begin{tabular}{|c|c|c|c|c|c|c|c|}
\hline Sample code & TTI (s) & $\begin{array}{c}\mathrm{pkHRR} \pm \sigma \\
\left(\mathrm{kW} / \mathrm{m}^{2}\right)\end{array}$ & $\begin{array}{l}\text { THR } \pm \sigma \\
\left(\mathrm{MJ} / \mathrm{m}^{2}\right)\end{array}$ & $\begin{array}{c}\mathrm{SPR} \pm \sigma \\
\left(10^{-3} \cdot \mathrm{m}^{2} / \mathrm{s}\right)\end{array}$ & $\begin{array}{l}\mathrm{TSP} \pm \sigma \\
\left(\mathrm{m}^{2} / \mathrm{kg}\right)\end{array}$ & $\begin{array}{c}\text { MARHE } \pm \sigma \\
\left(\mathrm{kW} / \mathrm{m}^{2}\right)\end{array}$ & Wres $\pm \sigma(\%)$ \\
\hline Bamboo & $31 \pm 2$ & $502.4 \pm 23.4$ & $38.6 \pm 1.7$ & $21.4 \pm 1.8$ & $0.99 \pm 0.01$ & $191.5 \pm 8.3$ & $16.6 \pm 0.9$ \\
\hline MgAl-LB-6 h & $35 \pm 2$ & $367.0 \pm 5.1$ & $29.7 \pm 2.4$ & $9.7 \pm 1.3$ & $0.25 \pm 0.01$ & $130.2 \pm 1.7$ & $19.9 \pm 1.4$ \\
\hline MgAl-LB-12 h & $40 \pm 1$ & $320.0 \pm 20.6$ & $27.0 \pm 0.3$ & $6.0 \pm 0.3$ & $0.20 \pm 0.03$ & $118.6 \pm 9.1$ & $21.1 \pm 1.6$ \\
\hline MgAl-LB-24h & $42 \pm 3$ & $286.9 \pm 11.4$ & $25.7 \pm 0.4$ & $4.9 \pm 0.5$ & $0.11 \pm 0.01$ & $106.1 \pm 0.1$ & $22.9 \pm 0.8$ \\
\hline MgAl-LB-36 h & $45 \pm 2$ & $270.8 \pm 13.2$ & $25.6 \pm 0.4$ & $2.2 \pm 1.1$ & $0.16 \pm 0.03$ & $100.1 \pm 0.4$ & $23.0 \pm 1.1$ \\
\hline MgAl-LB-48 h & $43 \pm 3$ & $245.2 \pm 65.9$ & $26.5 \pm 0.2$ & $2.3 \pm 0.7$ & $0.10 \pm 0.03$ & $101.3 \pm 7.8$ & $25.4 \pm 0.5$ \\
\hline
\end{tabular}

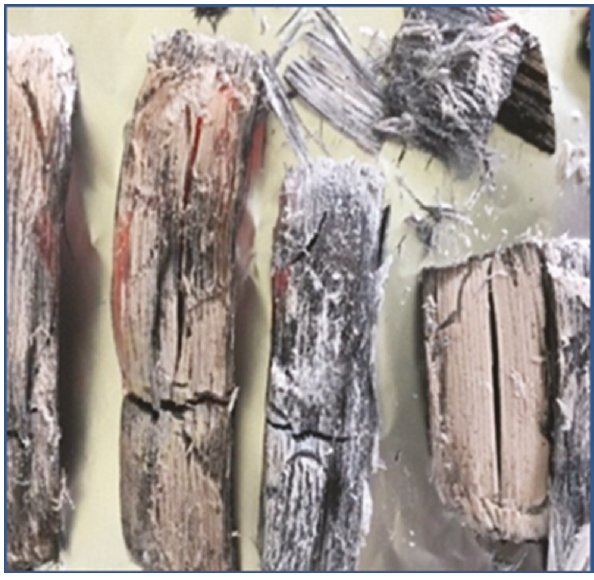

(a)

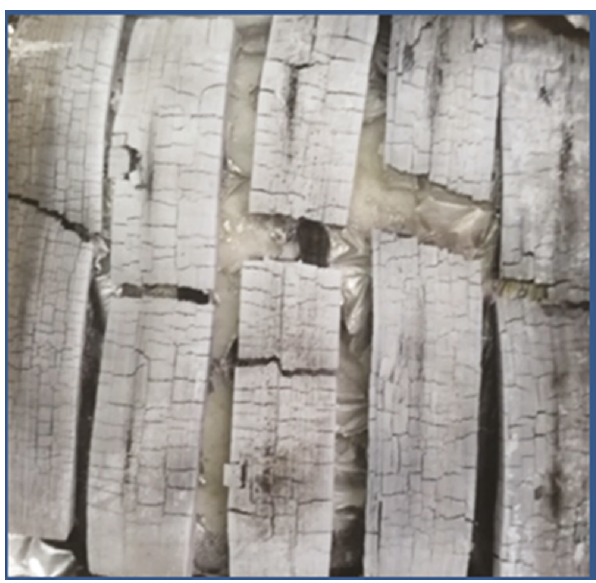

(c)

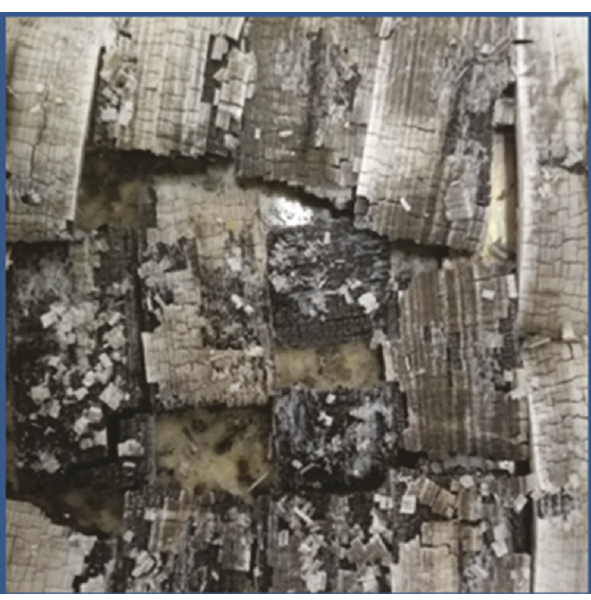

(b)

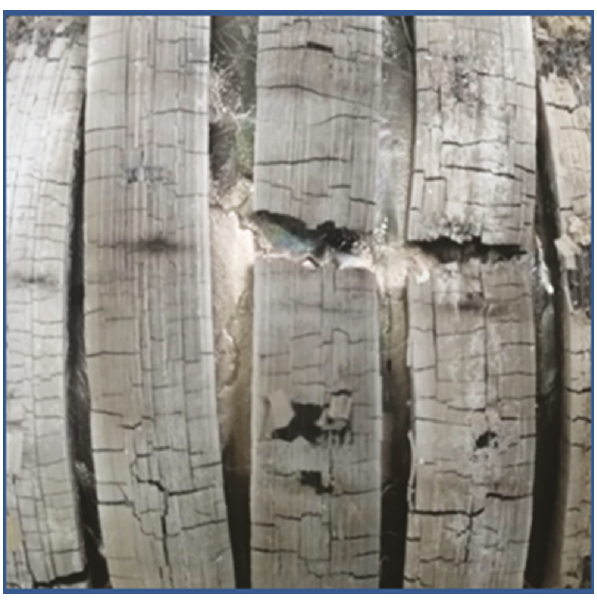

(d)

FIGURE 7: Images of the residues after the cone calorimeter test: (a) untreated bamboo, (b) MgAl-LB-6h, (c) MgAl-LB-24h, and (d) MgAl-LB- 48 h.

important to detect the smoke production when materials are burned. The SPR values and TSP of samples are shown in Figures 6(c) and 6(d) and Table 1. Compared with untreated bamboo, the SPR of MgAl-LBs prepared at different reaction times ( $6 \mathrm{~h}$ to $48 \mathrm{~h}$ ) decreased by $54.4 \%, 71.8 \%, 77.3 \%, 89.7 \%$, and $89.2 \%$, respectively; and the TSP of the MgAl-LBs decreased by $74.9 \%, 79.9 \%, 88.9 \%, 83.5 \%$, and $90.0 \%$, respectively. In addition, the SEA of the MgAl-LBs was smaller than that of untreated bamboo, which further indicates that MgAl-LBs have better smoke suppression performance (Figure 6(f)).

Figure 6(e) shows the ARHE of bamboo and the MgAlLBs. The maximum average rate of heat emission (MARHE) can be used as an indicator to measure the tendency for fire to develop under real conditions [26,27]. The MARHE value of untreated bamboo was $191.5 \mathrm{~kW} / \mathrm{m}^{2}$, and the MARHE values 


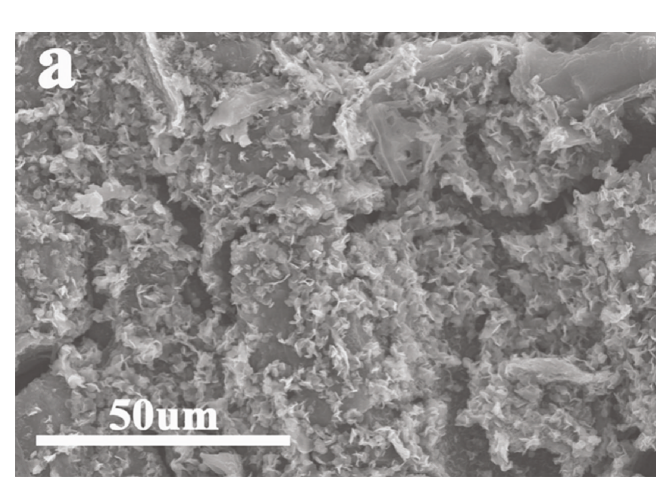

(a)

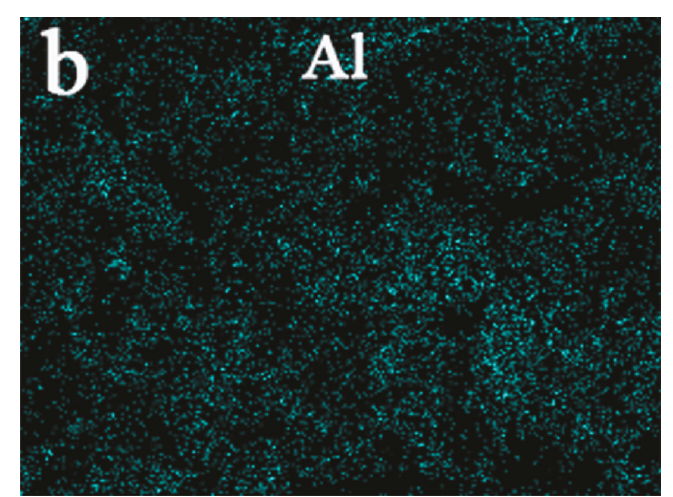

(b)

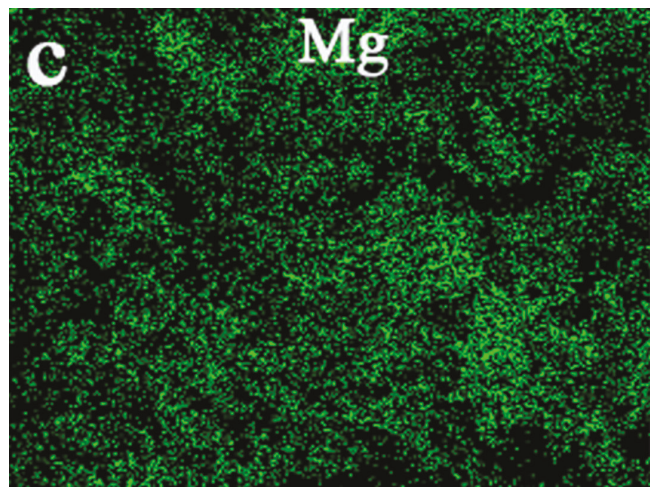

(c)

FIgURE 8: SEM image of the MgAl-LB-24h residue (a) and EDX mapping of the MgAl-LB-24h residue based on a mapping model investigation $(b, c)$.

of the MgAl-LBs ( $6 \mathrm{~h}$ to $48 \mathrm{~h}$ ) decreased to $130.2 \mathrm{~kW} / \mathrm{m}^{2}$, $118.6 \mathrm{~kW} / \mathrm{m}^{2}, 106.1 \mathrm{~kW} / \mathrm{m}^{2}, 100.1 \mathrm{~kW} / \mathrm{m}^{2}$, and $101.3 \mathrm{~kW} / \mathrm{m}^{2}$, respectively. This reduction indicates that MgAl-LDH can indeed diminish the tendency for fire to develop.

As shown in Figure 7, the residue of untreated bamboo after burning was mainly grayish white ash with a small amount of carbon blocks (Figure 7(a)). The residue of the MgAl-LBs after burning had some white ash on the surface, but the carbon shape basically maintained the original appearance of bamboo, which indicates that MgAl-LDH is beneficial to promote the carbon formation of bamboo during combustion. In particular, the residues of MgAl-LB-24h and MgAl-LB-48 h seem to be more complete and harder than the residue of MgAl-LB-6h (Figures 7(b)-7(d)), which indicates that uniform and dense MgAl-LDH is more favorable for carbon formation. The SEM and EDX results for the residual MgAl-LB coke after combustion are shown in Figure 8. Figure 8(a) shows that the surface of the burnt bamboo had dense white particles. The elemental analysis of the area revealed uniform and dense magnesium and aluminum on the surface of the bamboo (Figures $8(\mathrm{~b})$ and $8(\mathrm{c})$ ), which indicated that the surface LDHs decomposed into magnesium-aluminum oxide after the MgAl-LB were burned.

The above flame-retardant parameters indicated that the THR value of the MgAl-LB-36 h is the lowest, but the THR values of the MgAl-LB-24 $\mathrm{h}$ and MgAl-LB-36 $\mathrm{h}$ are very close (Figure 6(b) and Table 1). Compared to that of untreated bamboo, the TSP value of the MgAl-LB-24h is reduced the most (Figure 6(d) and Table 1). Furthermore, the TTI and Wres of the MgAl-LB-24 $\mathrm{h}$ are better than those of the other MgAl-LBs (Table 1). In addition, the morphology of the MgAl-LDH nanostructure is nearly stable on the surface of MgAl-LB-24h (Figure 6). The $24 \mathrm{~h}$ reaction time is a lowenergy reaction time compared to $36 \mathrm{~h}$ and $48 \mathrm{~h}$. Therefore, the $24 \mathrm{~h}$ reaction time is the optimal time for the MgAl-LB. The TG test and abrasion resistance analysis mentioned below were performed using the MgAl-LB-24h.

3.4. TG and TG-IR Analysis. Figure 9 shows that the thermal stability and thermal oxidative property of untreated bamboo and MgAl-LB were evaluated by the thermogravimetric (TG) in nitrogen and air atmosphere, respectively. TG under $\mathrm{N}_{2}$ is used to simulate the combustion behavior under the surface of the combustion material. The decomposition of the polymer until the volatilization part of polymer combustion begins was simulated by air TG [28].

In a nitrogen atmosphere, evaporation of adsorbed water causes untreated bamboo and MgAl-LB to lose weight for the first time. In the pyrolysis process, there are mainly three pyrolysis processes for untreated bamboo. The process takes place in different temperature ranges: $200-260^{\circ} \mathrm{C}$ for hemicellulose, $240-350^{\circ} \mathrm{C}$ for cellulose, and $280-500^{\circ} \mathrm{C}$ for lignin [28-30]. The main peak in the DTG curve is mainly due to the decomposition of cellulose (Figure 9(b)). According to the TG-DTG diagram of MgAl-LDH, during the 


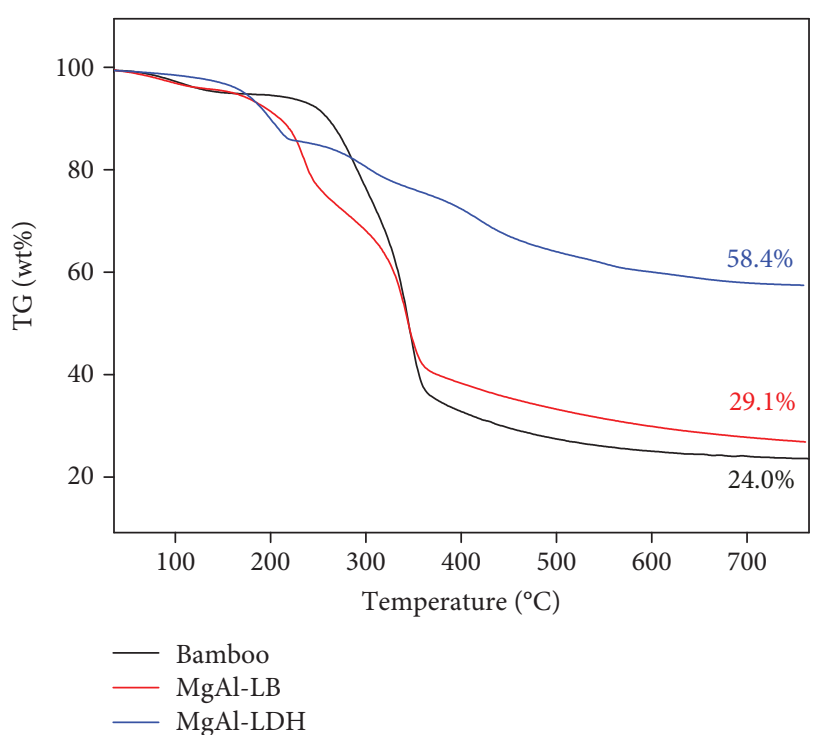

(a)

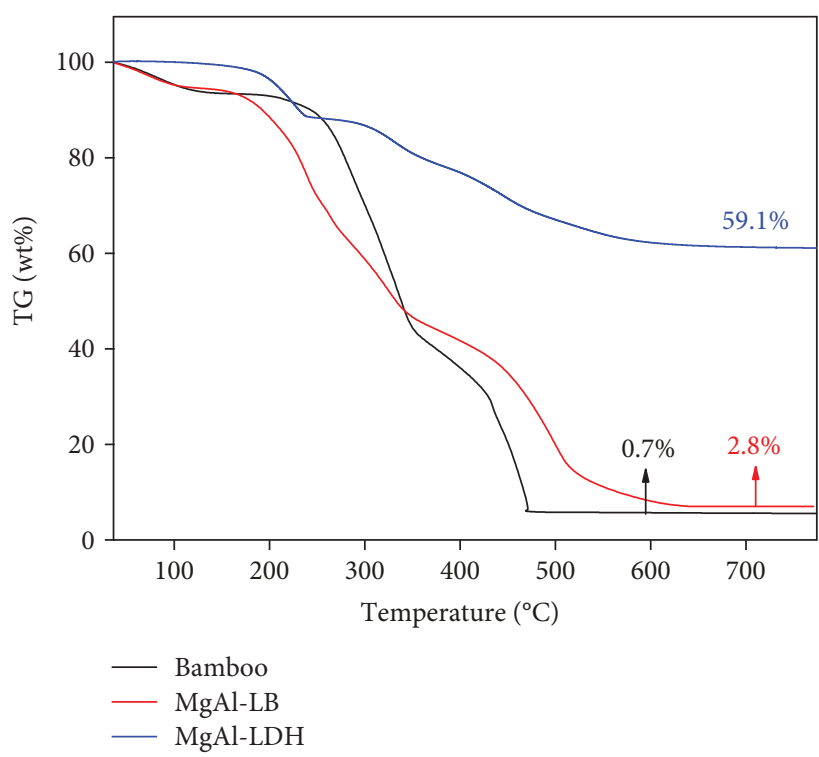

(c)

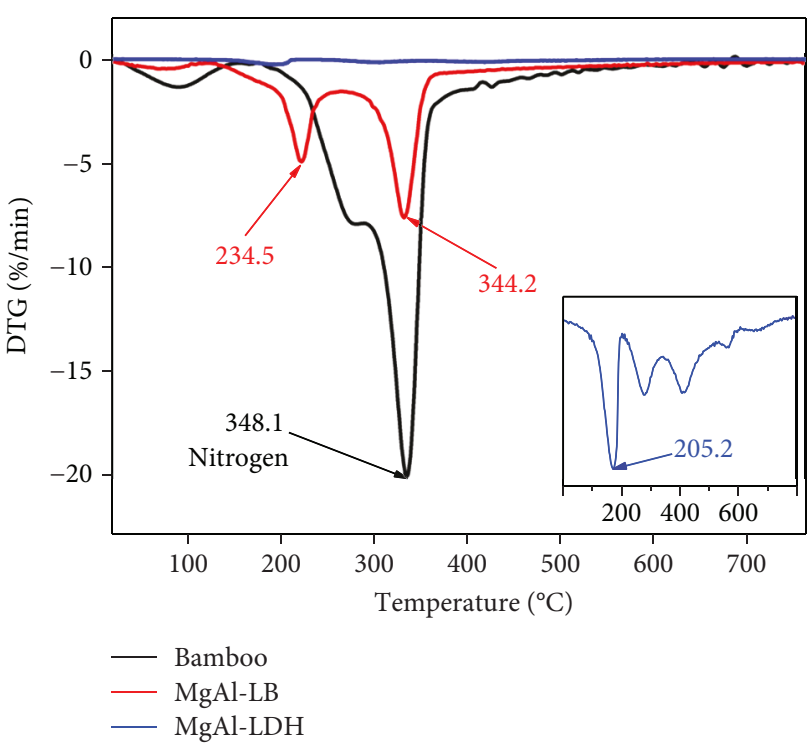

(b)

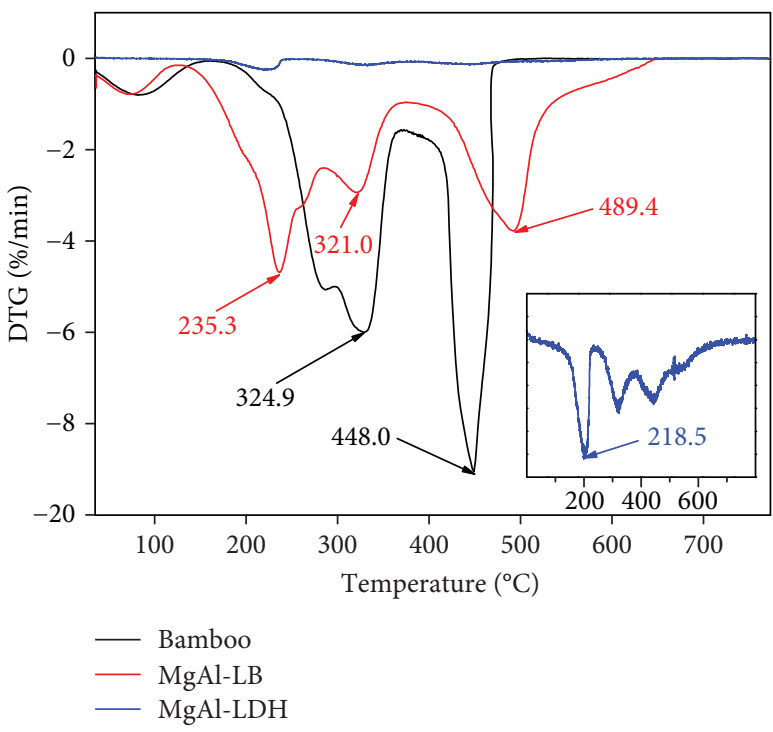

(d)

FIgure 9: Thermogravimetric (TG) and the differential of TG (DTG) curves for untreated bamboo and MgAl-LB in nitrogen (a, b) or air atmosphere $(\mathrm{c}, \mathrm{d})$. Note that MgAl-LB has a MgAl-LDH content of $1.8 \pm 0.1 \mathrm{wt} \%$.

heating process, MgAl-LDH experienced three weightless processes, namely, evaporation of adsorbed water, removal of interlayer ions, and removal of partial hydroxyl groups $[31,32]$ (such as a small map, Figure 9(b)). In contrast to the DTG curve of untreated bamboo, it can be clearly found that the DTG curve of MgAl-LB has a significant weight loss process at $234.5^{\circ} \mathrm{C}$, mainly because $\mathrm{MgAl}$ $\mathrm{LDH}$ evaporates a large amount of crystal water and adsorbed water.

The presence of MgAl-LDH coating has a certain influence on the pyrolysis of bamboo. From the TG curve (Figure 9(a)), the final residue of MgAl-LB was 29.1\% (the loading of $\mathrm{MgAl}-\mathrm{LDH}$ was $1.8 \%$ ), while the final residue of untreated bamboo was $24.0 \%$. This indicates that MgAl-
$\mathrm{LDH}$ is beneficial to promote the carbon formation of bamboo and improve the thermal stability of bamboo.

Under the air atmosphere conditions, it was found from the DTG curve that there were two degradation processes in the untreated bamboo (Figure 9(d)). The first degradation process occurs between 250 and $360^{\circ} \mathrm{C}$, which is related to the production of char from hemicellulose, cellulose, and lignin. The second degradation process takes place between 410 and $470^{\circ} \mathrm{C}$, which oxidizes char to $\mathrm{CO}$ and $\mathrm{CO}_{2}$ [33]. In the DTG curve, compared with untreated bamboo, MgAl-LB has a significant weight loss process between 170 and $250^{\circ} \mathrm{C}$, which is mainly attributed to the evaporation of crystal water and adsorbed water in MgAl-LDH (such as a small map, Figure $9(\mathrm{~d})$ ). Other weight loss processes are similar. In 


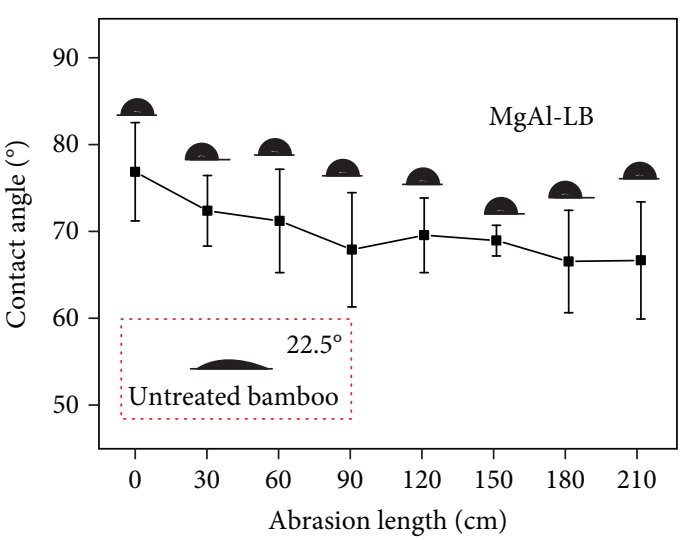

(a)

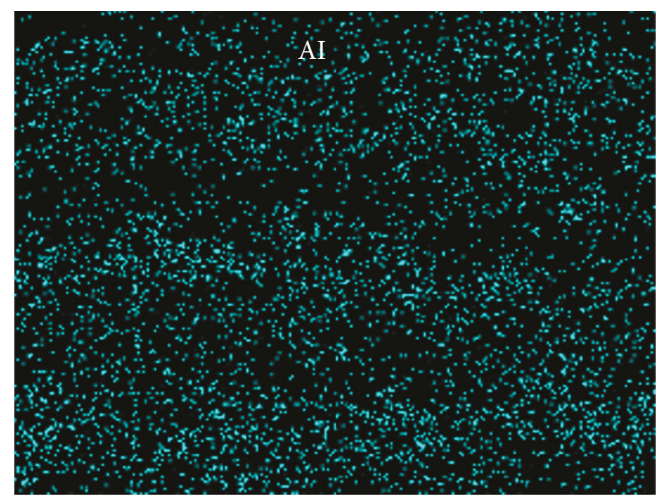

(c)

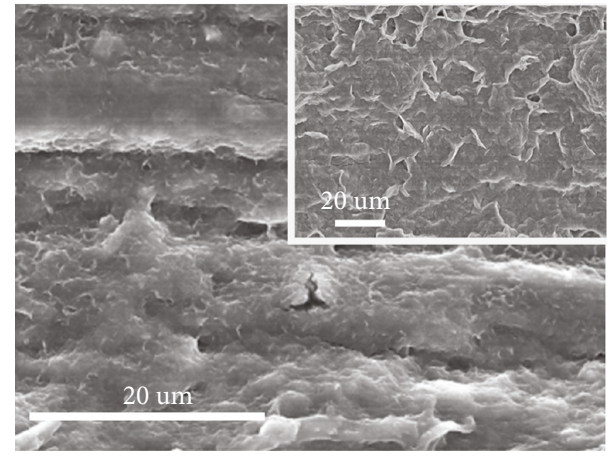

(b)

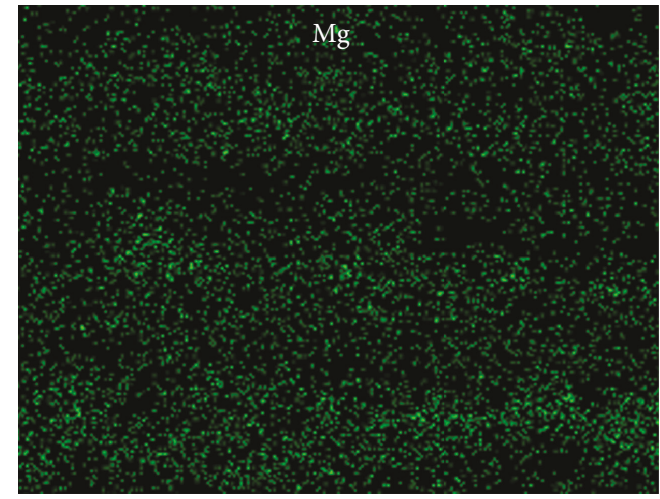

(d)

Figure 10: (a) Influence of abrasion length on contact angle of MgAl-LB-24h. (b) SEM image of MgAl-LB-24h after sliding $210 \mathrm{~cm}$. (c, d) EDX mapping of the MgAl-LB-24 h after abrasion based on a mapping model (b) investigation.

addition, comparing the char oxidation maximum degradation temperature of untreated bamboo and MgAl-LB, it was found that the char oxidation maximum degradation temperature of $\mathrm{MgAl}-\mathrm{LB}$ was significantly shifted to the right. It may be that $\mathrm{MgAl}-\mathrm{LDH}$ reduces the degradation kinetics. From the TG curve (Figure 9(c)), the final residue of MgAlLB was $2.8 \%$ (the loading of MgAl-LDH was $1.8 \%$ ), while the final residue of untreated bamboo was $0.7 \%$. The increase in the final residue of MgAl-LB is due to the increase in the weight of $1.8 \% \mathrm{MgAl}-\mathrm{LDH}$. The thermal stability behavior of untreated bamboo and MgAl-LB was analyzed by TGDTG under a nitrogen atmosphere and air atmosphere. It can be concluded that the inert gas released by MgAl-LDH and the inorganic coating formed by decomposition can promote the carbonization of bamboo and hinder the continuous decomposition of bamboo.

3.5. Abrasion Resistance. Since MgAl-LDH is used as a flame retardant coating on bamboo surfaces, its abrasion resistance is particularly important. In this experiment, the abrasion test was carried out to evaluate the abrasion resistance of the as-prepared MgAl-LB. As shown in Figure 10(a), the water contact angles were measured at every $30 \mathrm{~cm}$ of abrasion length, and all contact angles were measured by water droplets for 30 seconds (test method reference Figure 1). It can be seen from Figure 10(a) that after continuous abrasion of the MgAl-LB, its contact angle was gradually reduced and mainly distributed at $60-80^{\circ}$. However, it was still a larger contact angle than the contact angle of untreated bamboo $\left(22.5^{\circ}\right)$. This indicates that the MgAl-LDHs on the surface of the bamboo have a certain degree of abrasion resistance. In order to further analyze the abrasion resistance, the surface of the sample after smoothing $210 \mathrm{~cm}$ on a $1500-$ mesh sandpaper (under a pressure of $1000 \mathrm{~Pa}$ ) was observed by ESM. It can be seen from Figures $10(\mathrm{~b})-10(\mathrm{~d})$ that after the abrasion of MgAl-LB, the ab-oriented MgAl-LDHs on the surface are flattened, but the surface of the bamboo is not exposed. Therefore, the abrasion test proves that the MgAl$\mathrm{LDH}$ coating formed on the surface of the bamboo by situ reaction has good abrasion resistance.

\section{Conclusion}

In this study, MgAl-LDH coating on a bamboo surface was successfully prepared by an in situ one-step method. With the reaction time increased, the LDHs that formed in situ on the surface of the bamboo gradually became uniform and dense. When the reaction time reached $24 \mathrm{~h}$, the MgAl$\mathrm{LDH}$ that formed on the surface of the bamboo was saturated. Compared with those of untreated bamboo, the MgAl-LB-24h ignition time was extended by $11 \mathrm{~s}$, the total heat release was reduced by $28.1 \%$, and the total flue gas 
emissions were reduced by $88.9 \%$. The results show that LDHs can effectively improve the flame-retardant properties of bamboo, especially the smoke suppression performance. In addition, through the abrasion test, it was found that the LDH coating formed on the surface of the bamboo has good wear resistance in this experiment.

\section{Data Availability}

The data used to support the findings of this study are included within the article.

\section{Conflicts of Interest}

The authors declare that they have no conflicts of interest.

\section{Acknowledgments}

This work was financially supported by the Natural Science Foundation Key Project of Zhejiang Province (LZ17C160001).

\section{Supplementary Materials}

Graphical abstract: the in situ method is used to form a dense MgAl-LDH coating on the surface of bamboo, which can effectively improve the flame-retardant properties of bamboo. In particular, the smoke suppression performance of bamboo has been greatly improved, and its smoke suppression performance is reduced by $88.9 \%$ compared with untreated bamboo. (Supplementary Materials)

\section{References}

[1] L. Yu, J. Cai, H. Li, F. Lu, D. Qin, and B. Fei, "Effects of boric acid and/or borax treatments on the fire resistance of bamboo filament," BioResources, vol. 12, no. 3, pp. 5296-5307, 2017.

[2] H. Yu, C. Du, H. Liu et al., "Preparation and characterization of bamboo strips impregnation treated by silver-loaded thermo-sensitive nanogels," BioResources, vol. 12, pp. 83908401, 2017.

[3] J. C. Barbosa, J. R. M. da Silva, F. de Alvarenga, A. J. D. de Souza, V. A. de Araujo, and J. N. Garcia, "Simulation analysis of inservice bamboo and pine EGP composite flooring," Advances in Materials Research, vol. 1025-1026, pp. 233-240, 2014.

[4] A. A. Eliseev, A. V. Lukashin, A. A. Vertegel, V. P. Tarasov, and Y. D. Tret'yakov, "A study of crystallization of $\mathrm{Mg}-\mathrm{Al}$ double hydroxides," Doklady Chemistry, vol. 387, no. 4-6, pp. 339-343, 2002.

[5] X. Yao, Y. Hua, C. Du, Q. Huang, and C. Jin, "Research progress of LDHs fire retardant and its application in wood materials fire retarding," China Forest Products Industry, vol. 2, pp. 39-43, 2018.

[6] X. Xu, R. Lu, X. Zhao et al., "Fabrication and photocatalytic performance of a $\mathrm{Zn}_{x} \mathrm{Cd}_{1-x} \mathrm{~S}$ solid solution prepared by sulfuration of a single layered double hydroxide precursor," Applied Catalysis B: Environmental, vol. 102, no. 1-2, pp. 147-156, 2011.

[7] S. Hu, Y. Zhou, M. He et al., "Hollow Ni-Co layered double hydroxides-derived NiCo-alloy@g- $\mathrm{C}_{3} \mathrm{~N}_{4}$ microtubule with high-performance microwave absorption," Materials Letters, vol. 231, pp. 171-174, 2018.
[8] G. Zhang, L. Wu, A. Tang et al., "Growth behavior of MgAl-layered double hydroxide films by conversion of anodic films on magnesium alloy AZ31 and their corrosion protection," Applied Surface Science, vol. 456, pp. 419-429, 2018.

[9] Y. C. Li, Y. H. Yang, J. R. Shields, and R. D. Davis, "Layered double hydroxide-based fire resistant coatings for flexible polyurethane foam," Polymer, vol. 56, pp. 284-292, 2015.

[10] K. Zhu, Y. Wang, D. Tang et al., "Flame-Retardant Mechanism of Layered Double Hydroxides in Asphalt Binder," Materials, vol. 12, no. 5, p. 801, 2019.

[11] Y. Liu, Y. Gao, Q. Wang, and W. Lin, “The synergistic effect of layered double hydroxides with other flame retardant additives for polymer nanocomposites: a critical review," Dalton Transactions, vol. 47, no. 42, pp. 14827-14840, 2018.

[12] B. Guo, Y. Liu, Q. Zhang et al., "Efficient flame-retardant and smoke-suppression properties of $\mathrm{Mg}$-Al-layered doublehydroxide nanostructures on wood substrate," ACS Applied Materials \& Interfaces, vol. 9, no. 27, pp. 23039-23047, 2017.

[13] S. Liang, L. Zhang, Z. Chen, and F. Fu, "Flame retardant efficiency of melamine pyrophosphate with added Mg-Allayered double hydroxide in medium density fiberboards," BioResources, vol. 12, no. 1, pp. 533-545, 2016.

[14] X. Wang, E. N. Kalali, W. Xing, and D. Y. Wang, " $\mathrm{CO}_{2}$ induced synthesis of $\mathrm{Zn}-\mathrm{Al}$ layered double hydroxide nanostructures towards efficiently reducing fire hazards of polymeric materials," Nano Advances, vol. 3, pp. 12-17, 2018.

[15] S. Jia, H. Chen, S. Luo et al., "One-step approach to prepare superhydrophobic wood with enhanced mechanical and chemical durability: driving of alkali," Applied Surface Science, vol. 455, pp. 115-122, 2018.

[16] J. T. Kloprogge, D. Wharton, L. Hickey, and R. L. Frost, "Infrared and Raman study of interlayer anions $\mathrm{CO}_{3}{ }^{2-}, \mathrm{NO}_{3}{ }^{-}, \mathrm{SO}_{4}{ }^{2-}$ and $\mathrm{ClO}_{4}{ }^{-}$in $\mathrm{Mg} / \mathrm{Al}$-hydrotalcite," American Mineralogist, vol. 87, no. 5-6, pp. 623-629, 2002.

[17] A. Violante, M. Pucci, V. Cozzolino, J. Zhu, and M. Pigna, "Sorption/desorption of arsenate on/from Mg-Al layered double hydroxides: influence of phosphate," Journal of Colloid and Interface Science, vol. 333, no. 1, pp. 63-70, 2009.

[18] H. Pan, W. Wang, Q. Shen et al., "Fabrication of flame retardant coating on cotton fabric by alternate assembly of exfoliated layered double hydroxides and alginate," RSC Advances, vol. 6, no. 113, pp. 111950-111958, 2016.

[19] X. Guo, F. Zhang, S. Xu, D. G. Evans, and X. Duan, "Preparation of layered double hydroxide films with different orientations on the opposite sides of a glass substrate by in situ hydrothermal crystallization," Chemical Communications, vol. 44, no. 44, pp. 6836-6838, 2009.

[20] L. Wang, C. Li, M. Liu, D. G. Evans, and X. Duan, "Large continuous, transparent and oriented self-supporting films of layered double hydroxides with tunable chemical composition," Chemical Communications, no. 2, pp. 123-125, 2007.

[21] Z. Lü, F. Zhang, X. Lei, L. Yang, S. Xu, and X. Duan, "In situ growth of layered double hydroxide films on anodic aluminum oxide/aluminum and its catalytic feature in aldol condensation of acetone," Chemical Engineering Science, vol. 63, no. 16, pp. 4055-4062, 2008.

[22] B. Schartel and T. R. Hull, "Development of fire-retarded materials-interpretation of cone calorimeter data," Fire and Materials, vol. 31, no. 5, pp. 327-354, 2007. 
[23] K. M. Holder, R. J. Smith, and J. C. Grunlan, "A review of flame retardant nanocoatings prepared using layer-by-layer assembly of polyelectrolytes," Journal of Materials Science, vol. 52, no. 22, pp. 12923-12959, 2017.

[24] F. Carosio, J. Alongi, C. Paravidino, and A. Frache, "Improving the flame retardant efficiency of layer by layer coatings containing deoxyribonucleic acid by post-diffusion of hydrotalcite nanoparticles,” Materials, vol. 10, no. 7, p. 709, 2017.

[25] C. Du, Z. Zhou, H. Yu, Q. Huang, X. Yao, and C. Jin, "Smokeinhibiting properties and smoke characteristics of fireretardant bamboo scrimber in burning," Journal of Nanjing Forestry University (Natural Sciences Edition), vol. 41, pp. 163-168, 2017.

[26] G. Duggan and S. Kumar, "New fire classifications and fire test methods for the European railway industry: flame retardants," in Flame Retardants, Vol. 11, pp. 233-240, Interscience, 2004.

[27] F. Carosio, F. Cuttica, L. Medina, and L. A. Berglund, "Clay nanopaper as multifunctional brick and mortar fire protection coating-wood case study," Materials \& Design, vol. 93, pp. 357-363, 2016.

[28] Q. Fu, L. Medina, Y. Li, F. Carosio, A. Hajian, and L. A. Berglund, "Nanostructured wood hybrids for fire-retardancy prepared by clay impregnation into the cell wall," ACS Applied Materials \& Interfaces, vol. 9, no. 41, pp. 36154-36163, 2017.

[29] E. D. Tomak, E. Baysal, and H. Peker, "The effect of some wood preservatives on the thermal degradation of scots pine," Thermochimica Acta, vol. 547, pp. 76-82, 2012.

[30] M. Brebu and C. Vasile, "Thermal degradation of lignin-a review," Cellulose Chemistry and Technology, vol. 44, p. 353, 2010.

[31] X. Zhao, C. Zhou, B. Han, Z. Ji, L. Wang, and J. Wu, "Growth mechanism of curved $\mathrm{Mg}-\mathrm{Al}-\mathrm{CO}_{3}$ layered double hydroxide nanostructures in a one-pot assembly procedure under ambient pressure," RSC Advances, vol. 5, no. 26, pp. 19955-19960, 2015.

[32] X. Cheng, X. Huang, X. Wang, and D. Sun, "Influence of calcination on the adsorptive removal of phosphate by $\mathrm{Zn}-\mathrm{Al}$ layered double hydroxides from excess sludge liquor," Journal of Hazardous Materials, vol. 177, no. 1-3, pp. 516-523, 2010.

[33] E. Hedberg, A. Kristensson, M. Ohlsson et al., "Chemical and physical characterization of emissions from birch wood combustion in a wood stove," Atmospheric Environment, vol. 36, no. 30, pp. 4823-4837, 2002. 


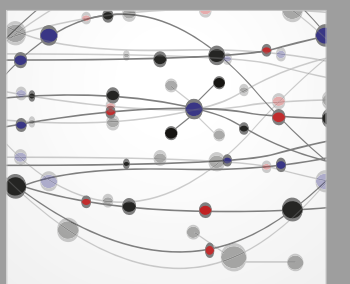

The Scientific World Journal
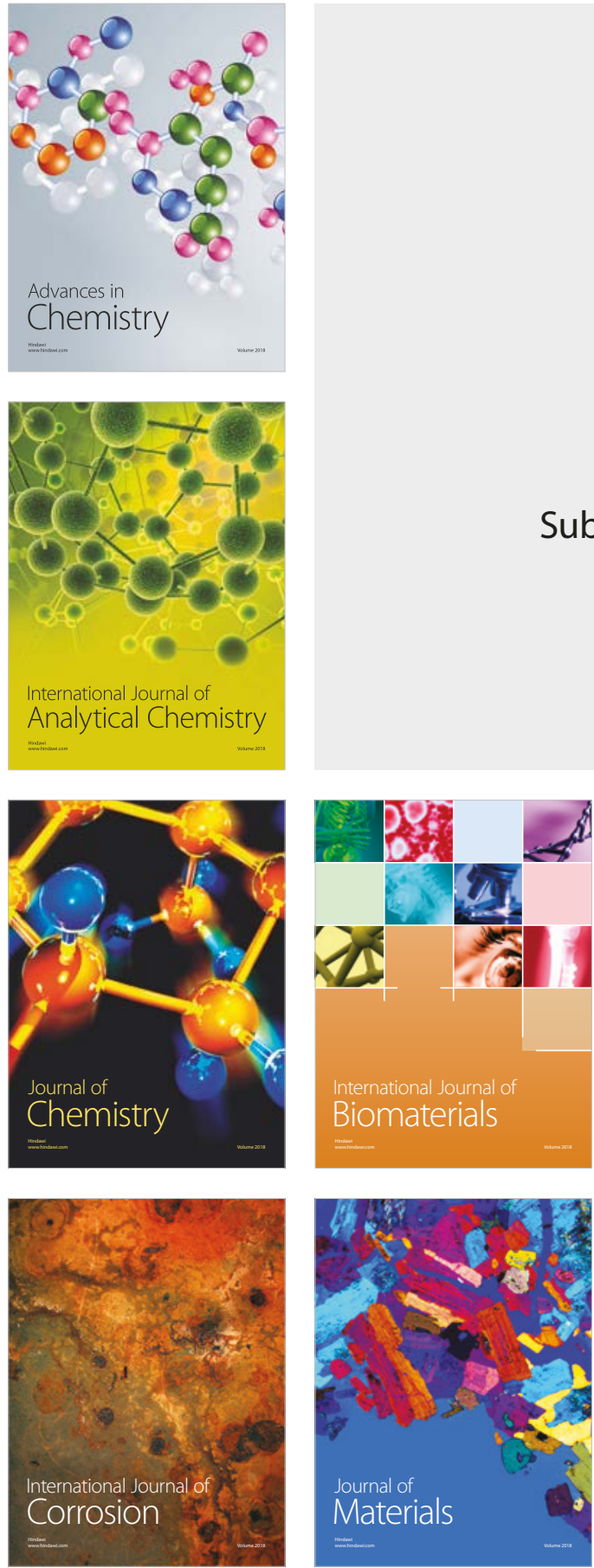

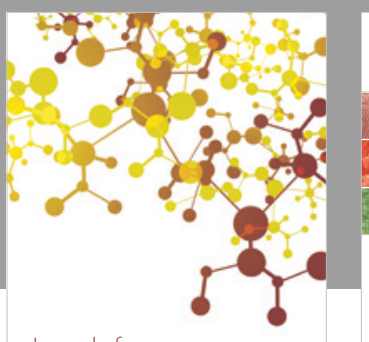

Journal of

Applied Chemistry
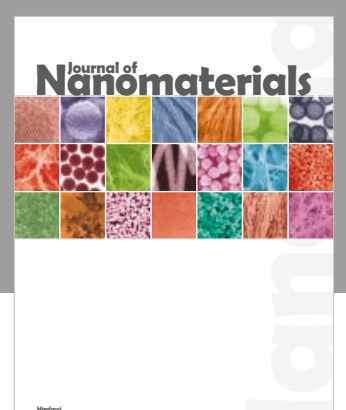

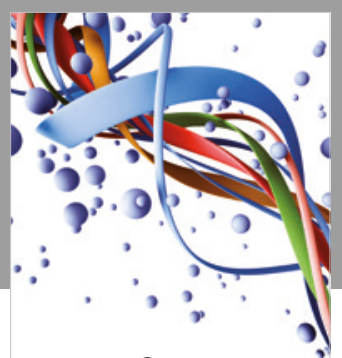

Scientifica

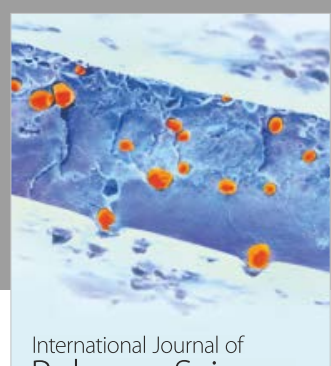

Polymer Science

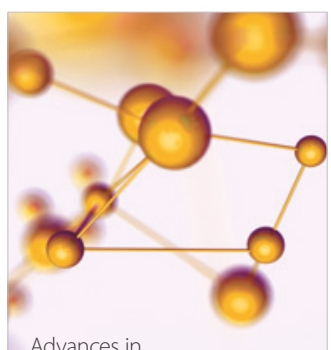

Physical Chemistry
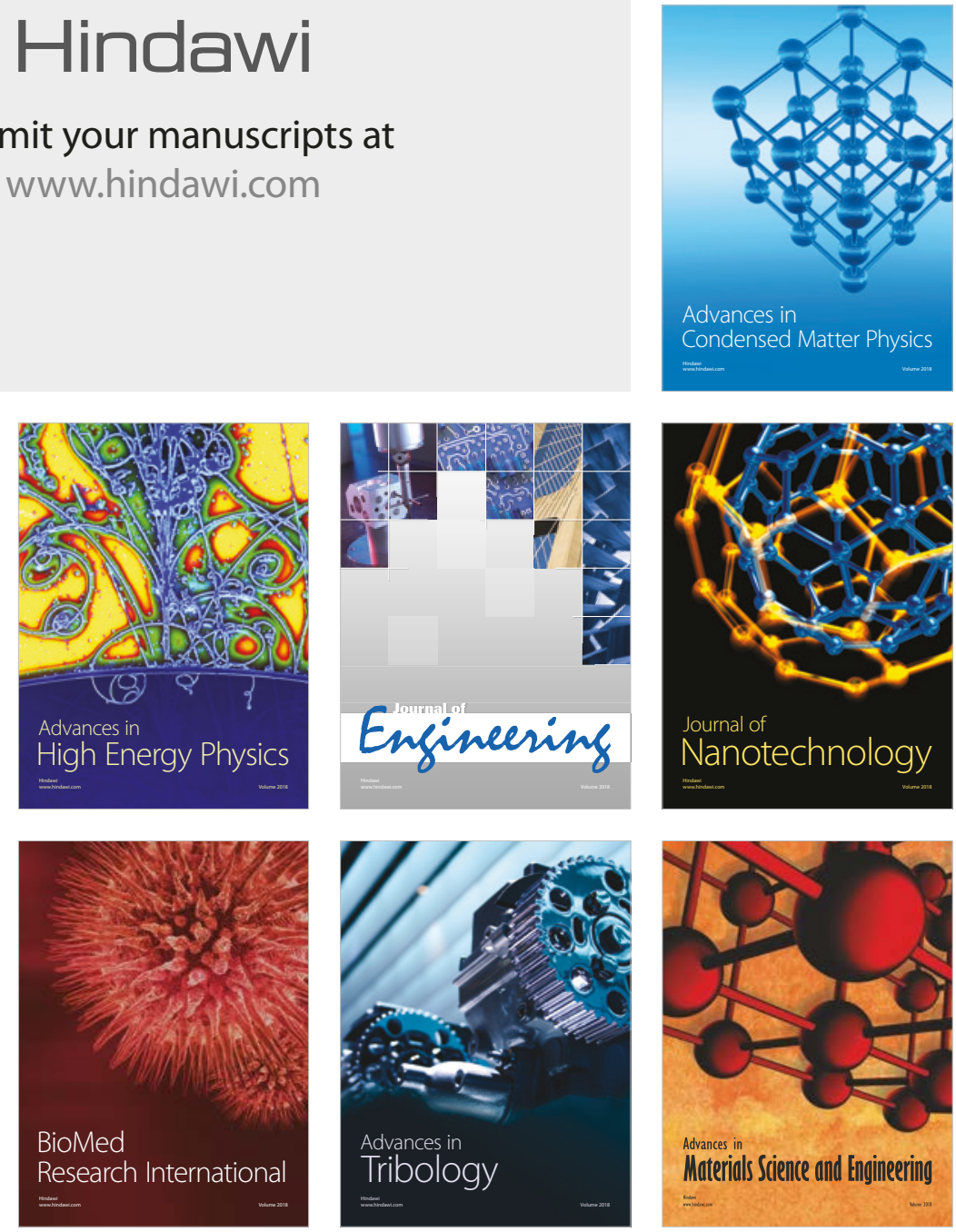